\title{
Utilização de Portfólios na Criação de Relatos e Reflexão Sobre o Erro em Programação para Alunos do Ensino Superior
}

\author{
Fernanda Castro ${ }^{1}$, Patricia Tedesco ${ }^{1}$ \\ ${ }^{1}$ Centro de Informática, Universidade Federal de Pernambuco, Recife, Pernambuco, Brazil \\ $\{\mathrm{mfcc}$, pcart\}@cin.ufpe.br.
}

\begin{abstract}
Crucial to the Computing curriculum, programming is considered to be one of its most difficult topics, since it requires the abilities of abstraction, reasoning and representation. In its complexity, the activity becomes susceptible to failure. Theories such as Vygostky's treat reflection on error as an integral part of the learning process. Given that the educational potential of the error is usually wasted due to a negative bias, this work aims to investigate, through the realization of a quantitative experiment with a focus on Higher Education, the use of portfolios in the creation of reports that promote reflection on mistakes made in programming disciplines.
\end{abstract}

\begin{abstract}
Resumo. Crucial para o currículo de cursos de Computação, a programação é considerada um de seus tópicos mais difíceis, pois exige habilidades de abstração, raciocínio e representação. Em sua complexidade, a atividade torna-se suscetível a falhas. Teorias como a de Vygostky tratam a reflexão sobre o erro como parte integrante do processo de aprendizagem. Dado que o potencial educador do erro costuma ser desperdiçado sob uma caracterização de viés negativo, este trabalho tem como objetivo investigar, através da realização de um experimento quantitativo com foco no Ensino Superior, o uso de portfólios na criação de relatos que promovam a reflexão sobre erros cometidos em disciplinas de programação.
\end{abstract}

\section{Introdução}

A habilidade de programar é uma das bases de Cursos de Computação. No entanto, o ensino de programação e algoritmos é frequentemente considerado um dos tópicos mais difíceis do curso, com disciplinas apresentando taxas altas de reprovação e desistência [WATSON; LI, 2014]. Fatores de diversas naturezas (e.g. metodológicos, estruturais) contribuem para a queda de desempenho neste tipo de conteúdo [MENEZES; NOBRE, 2002], indicativos de que talvez ainda não se conheça uma forma ideal de educar em Computação.

Além disso está o fato de que a programação e o código em si não constituem o objetivo final da atividade de programar. O real produto a ser desenvolvido pelo aluno é a resolução de um problema. O processo de programar exige que o aluno compreenda uma questão em seus diversos aspectos, abstraindo-a e expressando-a na sintaxe correta da linguagem. Atividades desta natureza tornam-se especialmente suscetíveis a falhas [GOMES et al., 2015], o que contribui para que os estudantes as considerem como tópicos difíceis. No caso do ensino de programação, Mora, Kumar e Renumol (2011) citam a depuração como uma das fases mais importantes da aprendizagem. Nela, o aluno é capaz de visualizar, manipular, corrigir e 
VII Congresso Brasileiro de Informática na Educação (CBIE 2018)

Anais do XXIX Simpósio Brasileiro de Informática na Educação (SBIE 2018)

aperfeiçoar sua solução, levando a um refinamento da habilidade de codificação adquirida.

No entanto, perdura em nossa sociedade a caracterização do erro sob um viés negativo [KUTZKE; DIRENE, 2016]. Ao errar, o aluno sente-se desmotivado, atribuindo o equívoco à falta de um dom natural. Nesta visão, o acerto é associado ao talento e à afinidade, ao invés de a um conjunto de competências construído gradualmente por meio de estudo e prática. Tal visão é identificada por Cannon e Edmondson (2005) como uma característica cultural.

Dado que a atividade de depuração é uma das mais importantes e que está atrelada ao processo de reflexão sobre falhas, é importante desmistificar o erro em programação e incentivá-lo como oportunidade de aprendizado. Em busca de alternativas para contemplar tal problema, este estudo utiliza como referência a previsão publicada pela Envisioning Technology Research Foundation ${ }^{1}$. A fundação estima que, por volta do ano 2030, avaliações tradicionais serão substituídas por atividades de projeto que agreguem valor ao "portfólio" do aluno. Barrett (2010) define portfólio como uma coleção de evidências que mostra a jornada de aprendizagem do aluno, onde uma evidência é qualquer registro ou artefato catalogado na ferramenta, como diários de classe, avaliações ou trabalhos escolares. O portfólio é uma plataforma centralizadora, que provê ao aluno uma visão analítica de seu aprendizado como um todo, sendo possível utilizá-la na criação de relatos que fomentem a reflexão do aluno sobre o erro.

Este trabalho tem como objetivo investigar, por meio da realização de um experimento, o uso de portfólios para a criação de relatos visando a reflexão sobre o erro, com foco em disciplinas de programação do Ensino Superior. A Seção 2 apresenta uma discussão sobre portfólios eletrônicos e sobre como o erro em programação é tratado em sala de aula. A seguir, a Seção 3 apresenta as principais plataformas de portfólios existentes no mercado. A Seção 4 traz a metodologia e planejamento do experimento. A Seção 5 discute a realização do experimento e os resultados obtidos. A Seção 6 apresenta as considerações finais e possíveis trabalhos futuros.

\section{Fundamentação Teórica}

O valor pedagógico do erro como parte integrante do aprendizado é um conceito relativamente recente [SERCONEK, 2011]. Embora tenhamos presenciado transformações nas práticas de ensino ao longo das últimas décadas, a conotação negativa do erro perdura e até extrapola o âmbito educacional [CANNON; EDMONDSON, 2005]. Associamos o erro à falta de talento e aptidão. Em Kutzke (2015), argumenta-se que, ao moldar estudantes para repudiar o erro, cria-se um processo onde a falha denota falta de empenho. Tal processo é chamado pelo autor de culpabilização do aluno. A culpabilização do aluno traz ainda outro viés, que é a isenção do professor e da instituição de ensino. Ao transferir a responsabilidade de reparação para os estudantes, deixa-se de revisar práticas de ensino, materiais e métodos [KUTZKE, 2015].

Outra problemática identificada é a concepção do erro enquanto um produto final indesejado: ou se obtém êxito ou se obtém fracasso. Porém, tal pensamento mostra-se antagônico à teoria de Vygostky acerca da criação de conceitos espontâneos e científicos [VYGOTSKY, 2009]. Para ele, são chamados de espontâneos os conceitos que independem de instrução formal e que são adquiridos por meio de vivências e experimentações. Conceitos científicos, por sua

\footnotetext{
${ }^{1}$ http://envisioning.io/education/.
} 
VII Congresso Brasileiro de Informática na Educação (CBIE 2018)

Anais do XXIX Simpósio Brasileiro de Informática na Educação (SBIE 2018)

vez, são aqueles formalizados no processo de aprendizagem. Embora em alguns casos ocorram conflitos entre conceitos espontâneos e científicos, Vygotsky afirma ser importante compreendê-los não como entidades opostas, mas sim relacionadas.

Para ele, o conhecimento espontâneo viabiliza a aquisição de conhecimento científico: ao manipular novas informações, o estudante constrói seu entendimento acerca de conceitos científicos mais complexos. Vygotsky aponta para um entendimento gradual dos conceitos, um processo em constante expansão. Assim, é natural que conceitos científicos parcialmente compreendidos levem ao erro, que evidencia uma tentativa de significar o que está sendo aprendido. Deste modo, o erro é mais uma etapa da significação, onde o aluno tem a oportunidade de criar novas conexões e avançar seu entendimento sobre um conceito a um estado de maior completude.

Erros em programação podem ser classificados em três tipos [CHAN MOW, 2012]. Erros de sintaxe são erros de digitação ou mau uso dos elementos específicos da linguagem, tal como mau posicionamento de chaves e colchetes no código. Já erros semânticos referem-se a códigos sintaticamente corretos, mas que apresentam erros de significado, como a chamada de uma função não implementada no código. Erros lógicos, por sua vez são aqueles que não podem ser identificados pelo compilador, sendo mais difíceis de diagnosticar. Consistem tanto em erros que inviabilizam a execução do programa quanto erros que produzem uma saída inesperada ou incorreta. Exemplos de erros lógicos são chamadas a variáveis não inicializadas, situações de deadlock ou simplesmente a entrega de um resultado que não atende às especificações desejadas.

De acordo com Kutzke e Direne (2016), é preciso mediar os três tipos de erro. Isto significa acompanhar de perto o processo de depuração, dando espaço para que o aluno reflita e experimente novas abordagens. Outros autores também apontam o papel do professor na mediação da depuração [MARTINS, 2013] [SERCONEK, 2011].

Diante do exposto, surge a necessidade de criar ferramentas capazes de prover suporte à mediação da depuração, agindo tanto em auxílio do aluno quanto do professor. Considerando a literatura das últimas duas décadas, é possível notar que as poucas ferramentas propostas são costumeiramente voltadas para o diagnóstico e correção automática dos erros [MORE; KUMAR; RENUMOL, 2011], comum sobretudo nas funcionalidades de ambientes de programação. Tais abordagens, no entanto, impedem um processo reflexivo por parte dos estudantes.

\subsection{Portfólios e a Criação de Relatos}

A utilização de portfólios em sala de aula remonta aos anos 80 [BUTLER, 2006], tendo origem na Educação Infantil, onde a produção de trabalhos de classe a serem catalogados costuma possuir maior volume. Porém, ao longo do tempo, o portfólio foi sendo adotado em diferentes segmentos. E, conforme o meio digital conquistou seu espaço, o portfólio também modernizou-se, sendo apresentado em versões eletrônicas e online, afastadas do papel.

Existem três propósitos fundamentais que podem ser identificados em portfólios, sendo eles: aprendizagem, prestação de contas e marketing [BARRETT; CARNEY, 2005]. O propósito de aprendizagem documenta o desenvolvimento do aluno, provendo desafios e reflexões, 
VII Congresso Brasileiro de Informática na Educação (CBIE 2018)

Anais do XXIX Simpósio Brasileiro de Informática na Educação (SBIE 2018)

colocando o estudante como personagem central e audiência do portfólio. O senso de propriedade torna-se destaque: o estudante possui liberdade para utilizar o portfólio de maneira personalizada e conforme seus objetivos pessoais [BARRETT, 2010].

Já o propósito de prestação de contas é utilizado para documentar a conquista de habilidades e competências pré-estabelecidas, por exemplo, por uma instituição de ensino. $\mathrm{O}$ portfólio focará na visão de produto, sendo uma ferramenta feita para o aluno (que dispõe da possibilidade de acompanhar seu desempenho e identificar suas deficiências), mas não pelo aluno. Podemos compreendê-los como uma evolução dos boletins tradicionais.

Por fim, o propósito de marketing funciona como vitrine, onde são exibidos os melhores trabalhos e contribuições do estudante para posterior análise de terceiros. A seleção dos melhores trabalhos, contudo, é um método que acaba por eliminar a possibilidade de avaliações mais profundas, uma vez que o processo de aprendizagem não é registrado por inteiro no portfólio em prol apenas dos melhores resultados. Este tipo de portfólio apresenta-se como um produto, sendo capaz de substituir currículos ou diplomas tradicionais, atestando a competência do candidato.

Embora a junção de múltiplos propósitos dentro de um mesmo portfólio seja viável, Barrett afirma ser preciso estar atento à resolução de conflitos [BARRETT, 2010]. Visando a criação de relatos, é importante garantir que os alunos sintam-se seguros para compartilhar seus fracassos e opiniões com sinceridade, algo que não seria possível caso, por exemplo, este mesmo portfólio fosse utilizado para conseguir uma vaga no mercado de trabalho. Tais questões precisam ser trabalhadas com cuidado.

O uso de relatos sistemáticos na promoção da reflexão, onde o aluno descreve suas experiências, na forma escrita, também não é uma iniciativa recente [BUTLER, 2006]. De fato, desde os anos 80, portfólios já eram utilizados como diários de classe em algumas instituições da Educação Básica [BARRETT, 2004], e trabalhos apontam sua presença também em cursos superiores da área de Saúde [ELANGO; JUTTI; LEE, 2005]. Argumenta-se que através do registro escrito das práticas, cria-se uma oportunidade para refletir sobre os conhecimentos adquiridos. E embora conceitualmente relatos sistemáticos possam ser realizados utilizando caneta e papel, tal abordagem pode mostrar-se pouco atrativa ao aluno. Para estudantes de cursos de Computação no Ensino Superior, por exemplo, torna-se desejável o uso de ferramentas online, facilmente acessíveis e persistentes, que possam ser acopladas a outros sistemas, como é o caso dos portfólios eletrônicos. Além disso, a maior similaridade dos portfólio com a dinâmica das redes sociais pode ser um ponto a seu favor, por gerar um maior engajamento dos usuários. Esta mesma dinâmica é apontada por Barrett e Carney (2005) nos blogs e sites pessoais da internet.

O potencial do portfólio enquanto ferramenta promotora da reflexão sobre o erro pode ser evidenciado por sua capacidade de gerar senso de propriedade. Por senso de propriedade, Paulson, Paulson e Meyer (1991) referem-se à percepção de que o portfólio é uma representação da jornada de seu dono. Ao perceber-se refletido no portfólio, o estudante desenvolve sentimentos como orgulho, responsabilidade e dedicação. Ainda segundo os autores, tais sentimentos contribuem para uma visão mais analítica sobre as evidências armazenadas no portfólio, pois estas formariam a reputação e auto-imagem do estudante. Com base no que foi apresentado nesta seção, considerou-se importante levantar informações acerca das principais 
VII Congresso Brasileiro de Informática na Educação (CBIE 2018)

Anais do XXIX Simpósio Brasileiro de Informática na Educação (SBIE 2018)

plataformas de portfólios disponíveis para uso no mercado.

\section{Trabalhos Relacionados}

Este trabalho analisará três portfólios para o Ensino Superior. A escolha foi feita com foco na popularidade e disponibilidade de mercado. Todas as plataformas analisadas são oferecidas por meio eletrônico. Não foram encontradas plataformas voltadas ao ensino de programação ou que abordassem especificamente a criação de relatos.

O Foliotek ${ }^{2}$ une propósitos de prestação de contas e marketing. Com suporte tanto para o aluno quanto para instituições de ensino, serve como um repositório de projetos desenvolvidos. Os projetos são avaliados pelos professores e posteriormente utilizados como currículo do estudante. O Foliotek encoraja que os alunos compartilhem seus portfólios com os demais estudantes. Porém, o Foliotek não possui mecanismos que facilitem a reflexão do aluno ou a mediação do professor neste processo. Assim, entende-se que o Foliotek pode ser adaptado como ferramenta para criação de relatos, mas tal abordagem não está prevista no escopo da plataforma.

O Seelio ${ }^{3}$ possui um perfil similar ao Foliotek, unindo os propósitos de prestação de contas e marketing. Porém, seu objetivo é formar uma vitrine para o mercado profissional. A plataforma conta com a possibilidade de selecionar quais informações aparecerão no portfólio, incentivando os alunos a disponibilizar apenas suas histórias de sucesso. Assim, é possível afirmar que o Seelio não possui um ambiente favorável à reflexão do aluno sobre o erro.

O Mahara ${ }^{4}$ é o único portfólio open source e que prevê a possibilidade de personalização e adequação ao contexto de cada instituição de ensino. Seu funcionamento é focado no espaço acadêmico como um todo: prevê, por exemplo, a criação de contas com diferentes perfis, como professores e administradores. A plataforma incentiva a colaboração dos alunos através da troca de feedbacks em fóruns compartilhados. Para professores e administradores, é possível acoplar frameworks de competências aos portfólios, que identificam pontos fortes e fracos de cada estudante. Embora possa ser adaptado, a criação de relatos não é uma prioridade do sistema.

Dentre os portfólios comerciais disponíveis atualmente para o Ensino Superior, existe pouca preocupação com o propósito de aprendizagem. Quanto ao uso de relatos escritos em papel, não foi encontrada bibliografia fora das áreas de Saúde e Educação. Assim, optou-se pela realização de um experimento, visando investigar qual o impacto da adoção de portfólios como meio para a produção de relatos que auxiliem na reflexão dos alunos sobre o erro.

\section{Metodologia e Planejamento do Experimento}

Durante a fase de planejamento, identificou-se a necessidade de investigar se o relato sistemático via portfólio seria capaz de influenciar na forma como alunos refletiam sobre o erro em programação. Tal hipótese não havia sido ainda evidenciada pelos estudos encontrados na literatura. Optou-se, então, por seguir a metodologia exposta em Sampieri, Collado e Lucio (2013) sobre o uso de métodos quantitativos: uma forma de quantificar as principais mudanças

\footnotetext{
2 https://www.foliotek.com/

${ }^{3}$ https://seelio.com/

${ }^{4}$ https://mahara.org/
} 
VII Congresso Brasileiro de Informática na Educação (CBIE 2018)

Anais do XXIX Simpósio Brasileiro de Informática na Educação (SBIE 2018)

dos alunos com relação ao modo como estes encaravam o erro antes e após a utilização do portfólio, identificando um possível ganho a partir do uso dos relatos.

O portfólio escolhido foi o Foliotek, visto que sua utilização é gratuita e independe da adoção do sistema pelo restante da instituição de ensino. Seu método de uso necessitou ser adaptado a fim de priorizar os relatos individuais dos alunos. A utilização desta plataforma, embora oportuna, é uma das principais limitações da pesquisa, pois não oferece o cenário ideal para criação e catalogação dos relatos de modo confortável.

O experimento proposto tem o objetivo de promover, ao longo de um semestre, a utilização de portfólios em disciplinas de programação. Consiste nas seguintes fases: apresentação do experimento para instituição e professores responsáveis; apresentação do experimento para alunos e coleta de termos de participação voluntária; divisão dos voluntários entre grupo teste e grupo controle; aplicação de questionário para coletar dados acerca do perfil dos sujeitos analisados; aplicação de questionário pré-experimento visando identificar o sentimento dos alunos com relação ao erro; somente para o grupo teste: criação de um portfólio para cada aluno voluntário no Foliotek, a fim de que estes cataloguem as evidências criadas no curso e relatem suas experiências diárias; após cobertura da ementa proposta na disciplina, aplicação de questionário pós-experimento visando identificar o sentimento dos alunos com relação aos erros (a ser aplicado em ambos os grupos); análise dos dados coletados.

\section{Condução do Experimento e Resultados Obtidos}

O experimento foi realizado em disciplinas introdutórias de programação de duas instituições do Ensino Superior de Pernambuco, sendo uma pública e outra particular. As disciplinas escolhidas possuíam currículos distintos: uma destinava-se a ensinar fundamentos da construção de sistemas web, enquanto a outra disciplina destinava-se a introduzir conceitos de programação através de um ambiente de desenvolvimento com sintaxe simplificada. Participaram do estudo 18 voluntários, sendo 8 participantes do grupo teste e 10 do grupo controle. A composição do grupo teste foi de 5 alunos da primeira instituição e 3 da segunda, enquanto o grupo controle contou com 5 alunos da primeira instituição e 5 da segunda. O perfil dos estudantes dos dois grupos foi similar, com a predominância de alunos com pouca ou nenhuma experiência em programação e que nunca haviam tido contato com portfólios ou relatos sistemáticos.

Os questionários consistiram de Escalas Likert, exibidas na Figura 1. Algumas das questões formam complementos ou simetrias com outras perguntas do questionário. Tal manobra tem o objetivo de checar a validade das respostas anteriores e evitar que o texto da questão influencie a resposta dos participantes [SAMPIERI; COLLADO; LUCIO, 2013]. As turmas foram acompanhadas ao longo de um semestre letivo.

Após um primeiro contato com os alunos, o Foliotek foi apresentado em sala pelos professores, que discorreram sobre as principais funcionalidades e sobre a metodologia de uso a ser adotada na disciplina. Os professores propuseram atividades e projetos que pudessem ser registrados na ferramenta. A cada novo exercício, os alunos eram convidados a compartilhar seu código no Foliotek, juntamente a um documento contendo comentários sobre erros, acertos e a experiência geral de aprendizado. Para auxiliá-los, foi disponibilizada uma guia de perguntas a serem respondidas sobre cada exercício catalogado, para fomentar o processo de reflexão sobre o 
VII Congresso Brasileiro de Informática na Educação (CBIE 2018)

Anais do XXIX Simpósio Brasileiro de Informática na Educação (SBIE 2018)

erro. Os alunos ficaram livres para registrar qualquer tipo de erro ou dificuldade, fossem eles erros sintáticos, semânticos ou lógicos. A guia consistiu em perguntas como "Quais foram as suas principais dificuldades?"ou "Quais assuntos abordados em sala de aula foram relevantes?".

\section{Me sinto motivado por exercícios e desafios difíceis.}

2. Quando cometo erros em exercícios ou não consigo resolvê-los, acho que o problema está em mim.

3. Pessoas talentosas ou mais inteligentes cometem menos erros em suas tarefas.

4. Costumo aprender observando meus próprios erros.

5. Se não consigo resolver um exercício, não devo ter aprendido muito sobre o assunto mostrado em aula.

6. Quando me deparo com exercícios difíceis e que não consigo resolver rapidamente, me sinto desmotivado.

7. Acredito que errar faz parte do meu processo de aprendizagem.

Figura 1. Perguntas dos questionários pré e pós experimento.

Com relação ao tipo de erro relatado nas evidências cadastradas, foi possível notar uma distinção entre o perfil das duas turmas. Na primeira turma, que lidava com linguagens de programação a fim de construir um sistema web, foi possível encontrar a predominância de erros lógicos e, em menor escala, semânticos, uma vez que a maior dificuldade dos alunos era conseguir integrar os diferentes módulos do programa e fazer com que as diferentes funções se comportassem conforme o esperado. Na segunda turma, destinada a aprender os fundamentos da programação, o número de relatos contendo erros semânticos e sintáticos foi maior.

Ao longo do semestre, os alunos relataram uma crescente familiaridade com o processo de reflexão sobre o erro, ficando mais à vontade para aprofundar suas reflexões e expor fatores pessoais, como, citando um dos exemplos apurados, a desatenção provocada por uma aula cujo horário ocorria após a jornada de trabalho do aluno. Quanto mais cadastravam evidências no portfólio, mais criavam os relatos segundo suas próprias narrativas. Houve ainda uma dificuldade inicial com a manipulação do Foliotek, cuja interface mostrou-se confusa. Os alunos também demonstraram interesse por uma versão mobile. No entanto, estas dificuldades foram superadas ao longo do semestre. Professores e pesquisadoras permaneceram acessíveis para auxiliar os alunos em suas dúvidas com relação à plataforma. Embora sugerido, não houve compartilhamento de relatos ou feedbacks entre os alunos, sobretudo por esta atividade não ser suportada pelo Foliotek, outra limitação deste experimento.

A Tabela 1 apresenta a comparação entre grupo teste e grupo controle, antes e após a realização do experimento. Segundo as recomendações de Sampieri, Collado e Lucio (2013) e considerando o caráter discreto e opinativo de escalas Likert, optou-se por verificar as medidas de média e moda de cada grupo e, para assegurar se houve ou não ganho significativo entre os resultados, foi realizado o Teste de Wilcoxon-MannWhitney [DANCEY; REIDY, 2013] devido 
VII Congresso Brasileiro de Informática na Educação (CBIE 2018)

Anais do XXIX Simpósio Brasileiro de Informática na Educação (SBIE 2018)

ao tamanho reduzido da amostra e a inexistência de uma distribuição normal. O nível de confiança considerado foi de $\alpha=0.05$. O resultado dos testes para cada pergunta encontra-se na última coluna da tabela ( $\mathrm{p}$-value).

Tabela 1. Comparação dos dados obtidos entre grupo teste e grupo controle.

\begin{tabular}{|c|c|c|c|c|c|c|c|c|c|}
\hline \multirow[b]{3}{*}{ Questão 1} & \multicolumn{4}{|c|}{ Grupo Teste } & \multicolumn{4}{|c|}{ Grupo Controle } & \multirow{3}{*}{$\begin{array}{l}\text { O Grupo Teste obteve } \\
\text { resultados melhores? } \\
\text { Sim }(\mathrm{p} \text {-value }=0,034)\end{array}$} \\
\hline & \multicolumn{2}{|c|}{ Pré-Experimento } & \multicolumn{2}{|c|}{ Pós-Experimento } & \multicolumn{2}{|c|}{ Pré-Experimento } & \multicolumn{2}{|c|}{ Pós-Experimento } & \\
\hline & $\mathrm{Me}=4$ & $\mathrm{Mo}=\{3,5\}$ & $\mathrm{Me}=4,5$ & $\mathrm{Mo}=5$ & $\mathrm{Me}=3,1$ & $\mathrm{Mo}=4$ & $\mathrm{Me}=3,6$ & $\mathrm{Mo}=4$ & \\
\hline Questão 2* & $\mathrm{Me}=3,5$ & $\mathrm{Mo}=4$ & $\mathrm{Me}=3,1$ & $\mathrm{Mo}=2$ & $\mathrm{Me}=3,7$ & $\mathrm{Mo}=4$ & $\mathrm{Me}=2,9$ & Mo & Não $(\mathrm{p}$-value $=0,817)$ \\
\hline Questão 3* & $\mathrm{Me}=3,3$ & $\mathrm{Mo}=4$ & $\mathrm{Me}=3$ & $\mathrm{Mo}=3$ & $\mathrm{Me}=3,8$ & $\mathrm{Mo}=\{3,4,5\}$ & $\mathrm{Me}=3,4$ & & Não \\
\hline Questão 4 & $\mathrm{Me}=4,1$ & $\mathrm{Mo}=4$ & $\mathrm{Me}=4,7$ & $\mathrm{Mo}=5$ & $\mathrm{Me}=3,4$ & & $\mathrm{Me}=3,5$ & Мo $=$ & (1) \\
\hline Questão 5* & $\mathrm{Me}=4,2$ & $\mathrm{Mo}=5$ & $\mathrm{Me}=2,6$ & $\mathrm{Mo}=2$ & $\mathrm{Me}=3,5$ & $\mathrm{Mo}=\{3,4\}$ & $\mathrm{Me}=3$ & & value $=0,341)$ \\
\hline Questão 6* & $\mathrm{Me}=3,1$ & $0=\{2,3,5\}$ & $\mathrm{Me}$ & $\mathrm{M}$ & & Mo $=4$ & $=3,6$ & & $0,008)$ \\
\hline Questão 7 & $\mathrm{Me}=4,3$ & $\mathrm{Mo}=5$ & $\mathrm{Me}=4,8$ & $\mathrm{Mo}=5$ & $\mathrm{Me}=5,2$ & Mo $=4$ & $\mathrm{Me}=3,8$ & Mo $=4$ & $\operatorname{Sim}(p$-value $=0,002)$ \\
\hline
\end{tabular}

Nem sempre a resposta que melhor denota a reflexão sobre o erro e o reconhecimento de seus benefícios segue a lógica numérica. Em alguns casos a discordância do aluno é desejada, gerando uma resposta de valor 1, e em outros o melhor é sua anuência, gerando uma resposta de valor 5. Assim, nem sempre uma média ou moda de valor alto representará um resultado ideal. A fim de evitar equívocos desta natureza, as questões cuja moda e média ideal é 1 foram indicadas na tabela com um asterisco. É possível notar que, de modo geral, o grupo teste obteve um desempenho melhor do que o apresentado pelo grupo controle, demonstrando uma maior evolução nos valores de média e moda em cinco das sete questões analisadas.

O grupo controle apresentou melhores resultados nas Questões 2 e 3, sobre a percepção do aluno sobre o erro enquanto evidência de falta de talento ou falha pessoal. Uma possibilidade para explicar este fato é a de que, por não compartilharem os portfólios uns com os outros e trocarem feedbacks com seus pares, os estudantes do grupo teste deixaram de conhecer o processo de aprendizagem dos colegas, o que poderia melhorar suas percepções sobre o erro. Porém, houve melhora para ambos os grupos.

A Questão 5, sobre a associação do erro com o não aproveitamento do que foi exposto em sala de aula, apresentou uma das maiores evoluções relativas entre grupo teste e controle (considerando média e moda). No entanto, o teste de hipótese para esta questão foi rejeitado. Porém, embora ambos os grupos tenham tido resultados pós-teste similares, a evolução individual de cada grupo não pode ser descartada. De fato, existe uma preocupação de que o Teste de Wilcoxon-Mann-Whitney possa ter deficiências em identificar alguns efeitos reais em escalas Likert ${ }^{5}$. Assim, o método aproxima a distribuição dos gráficos pós-experimento mas ignora as evoluções individuais de cada grupo. Diante deste impasse, optou-se por considerar que houve melhora nesta questão. Possivelmente, esta diferença deve-se ao fato de que, ao registrar a evidência no portfólio e dissertar sobre as principais dificuldades de cada exercício, os alunos refletem acerca dos conteúdos vistos em sala e os próprios raciocínios aplicados à tarefa.

As Questões 1 e 6, complementares com relação à motivação dos estudantes, apresentaram uma boa evolução por parte do grupo teste. Este resultado é coerente com o apresentado por [CAMBRIDGE, 2001], onde o uso constante do portfólio acaba por criar a

\footnotetext{
${ }^{5}$ How to Analyze Likert Scale Data: http://statisticsbyjim.com/hypothesis-testing/analyze-likert-scale-data/
} 
VII Congresso Brasileiro de Informática na Educação (CBIE 2018)

Anais do XXIX Simpósio Brasileiro de Informática na Educação (SBIE 2018)

sensação de avanço contínuo. Os alunos demonstram maior tolerância a atividades desafiadoras e erros, por entenderem se tratar de um novo passo evolutivo em seu aprendizado.

As Questões 4 e 7, relativas ao entendimento do erro como ferramenta de aprendizado, também apresentaram bons resultados no comparativo entre os dois grupos, um efeito esperado da promoção da reflexão sobre o erro. Na Questão 7, é possível observar que, além de melhora no grupo teste, houve também uma piora na média do grupo controle.

Embora o uso dos relatos não tenha influenciado no aspecto negativo cultural do erro, existiram ganhos em outros aspectos, como maior motivação diante de tarefas desafiadoras, compreensão do erro enquanto oportunidade de aprender e desassociação entre o erro e a não-compreensão dos assuntos abordados em sala. Assim, é possível afirmar que o uso de relatos via portfólio influenciou positivamente a forma como os alunos trataram o erro.

\section{Considerações Finais}

Este trabalho teve como objetivo investigar o uso de portfólios na criação de relatos para cursos de programação do Ensino Superior, com foco na reflexão e no aprendizado referentes aos erros cometidos. A motivação para esta investigação veio da necessidade de desmistificar o erro no ensino de programação, considerado uma das fases mais importantes da aprendizagem.

Embora o potencial reflexivo e centralizador dos portfólios esteja evidenciado na literatura e existam indícios positivos sobre o uso de relatos sistemáticos, não foram encontrados estudos voltados à reflexão sobre o erro no Ensino Superior, e nem estudos referentes ao uso de portfólios eletrônicos em disciplinas de programação, sobretudo com foco na criação de relatos. Diante deste cenário, foi montado um experimento para mensurar a evolução do sentimento dos alunos para com os erros cometidos. Participaram do experimento duas turmas de introdução à programação do Ensino Superior, ambas utilizando a plataforma Foliotek ao longo de um semestre. O experimento concluiu que o grupo submetido ao uso do Foliotek apresentou melhores resultados, lidando de maneira mais positiva com os erros cometidos.

Dentre as contribuições desta pesquisa está a discussão acerca da reflexão sobre o erro e sua interpretação em sala de aula; discussão sobre o uso de portfólios e seu potencial educativo através de relatos sistemáticos e estudo quantitativo acerca da adoção de portfólios eletrônicos em disciplinas de programação no Ensino Superior. Como trabalhos futuros, espera-se ter a oportunidade de acompanhar as turmas por períodos mais extensos, a fim de observar os efeitos da adoção do portfólio a longo prazo. Também planeja-se fazer uso de ferramentas próprias, desenvolvidas com foco exclusivo na aprendizagem. Por fim, espera-se ainda explorar outros paradigmas de programação e linguagens.

\section{Referências}

BARRETT, H. (2004). Differentiating Electronic Portfolios and Online Assessment Management Systems. SITE 2004 Conference Proceedings, [S.1.].

BARRETT, H. (2010). Balancing the two faces of eportfolios. Educação, Formação e Tecnologias, [S.1.].

BARRETT, H.; CARNEY, J. (2005). Conflicting Paradigms and Competing Purposes in Electronic 
VII Congresso Brasileiro de Informática na Educação (CBIE 2018)

Anais do XXIX Simpósio Brasileiro de Informática na Educação (SBIE 2018)

Portfolio Development. Educational Assessment - Assessing Technology Competencies, [S.1.].

BUTLER, P. (2006). A Review Of The Literature On Portfolios And Electronic Portfolios. , [S.1.].

CAMBRIDGE, L. B. (2001). Electronic Portfolios as Knowledge Builders. São Paulo: American Association for Higher Education.

CANNON, M.; EDMONDSON, A. (2005). Failing to Learn and Learning to Fail (Intelligently): how great organizations put failure to work to innovate and improve. Elsevier Long Range Planning, [S.1.].

CHAN MOW, I. (2012). Analyses of Student Programming Errors In Java Programming Courses. Journal of Emerging Trends in Computing and Information Sciences, v.3 [S.1.].

DANCEY, C.; REIDY, J. (2013). Estatística sem Matemática - 5a edição. Penso Editora. Porto Alegre.

ELANGO, S.; JUTTI, R.; LEE, L. (2005). Portfolio as a learning tool: students' perspective. Ann Acad Med Singapore, [S.1.], p.511-514.

GOMES, M. et al. (2015). Um estudo sobre erros em programação: reconhecendo as dificuldades de programadores iniciantes. I Workshop de Ensino em Pensamento Computacional, [S.1.].

KUTZKE, A. (2015). Informática educacional e a mediação do erro na educação: um estudo teórico-crítico e uma proposta de instrumento computacional (tese). Doutorado em Informática. Universidade Federal do Paraná, [S.1.].

KUTZKE, A.; DIRENE, A. (2016). Mediação do erro no ensino de programação de computadores: fundamentos e aplicação da ferramenta farma-alg. Anais dos Workshops do Congresso Brasileiro de Informática na Educação, [S.1.].

MARTINS, L. M. (2013). O Desenvolvimento do Psiquismo e a Educação Escolar: contribuições à luz da psicologia histórico-cultural e da pedagogia histórico-crítica. São Paulo: SP: Autores Associados.

MENEZES, C.; NOBRE, I. (2002). Um ambiente cooperativo para apoio a cursos de introdução a programação. Congresso da Sociedade Brasileira de Computação, [S.1.].

MORE, A.; KUMAR, J.; RENUMOL, V. (2011). Web based programming assistance tool for novices. IEEE International Conference on Technology for Education, [S.1.].

PAULSON, F. L.; PAULSON, P. R.; MEYER, C. (1991). What makes a portfolio a portfolio? Educational Leadership Journal, [S.1.].

SAMPIERI, R. H.; COLLADO, C. F.; LUCIO, M. P. B. (2013). Metodologia de pesquisa - 5a edição. Porto Alegre: AMGH.

SERCONEK, G. C. (2011). As perspectivas de conhecimento e o enfoque histórico-cultural de mediação do erro. Anais do V Encontro Brasileiro de Educação e Marxismo: Marxismo, Educação e Emancipação Humana, [S.1.].

VYGOTSKY, L. S. (2009). A construção do pensamento e da linguagem. São Paulo: Martins Fontes.

WATSON, C.; LI, F. (2014). Failure Rates in Introductory Programming Revisited. Proceedings of the 2014 conference on Innovation technology in computer science education (ITiCSE '14), [S.1.]. 